\title{
The Hand that Rocked the Cradle: A Critical Analysis of Rockefeller Philanthropic Funding, 1920-1960
}

\author{
Brian J. Low
}

\begin{abstract}
Past research into the mental hygiene movement in Canada and the United States has tended to view it in isolation from co-temporary projects funded by Rockefeller philanthropy, such as mass communications research. The mental hygiene campaign aimed to modify adult-child relations by reducing the influence parents and teachers held over children's personality development; the central aim of mass communications research was the development of conformity of opinion. One a project of social engineering, the other of social control, the two projects combined appear to have possessed considerable potential to work in concert to shift weight in the socializing matrix from families and schools to the media at the outset of the post-World War II baby boom.
\end{abstract}

La recherche effectuée sur le mouvement d'hygiène mentale au Canada et aux États-Unis a eu tendance à considérer le mouvement séparément des projets contemporains financés par la philanthropie Rockefeller, tel celui de recherche en communications de masse. La campagne d'hygiène mentale visait à modifier les relations adulte-enfant en réduisant l'influence que les parents et les enseignants exerçaient sur le développement de la personnalité de l'enfant; l'objectif principal de la recherche en communications de masse était le développement de la conformité d'opinion. Le premier projet était de l'ordre de l'ingénierie sociale, le second du contrôle social. Mais, réunis, les deux projets semblent avoir possédé des possibilités considérables de concertation afin de transférer, des familles et des écoles aux médias, la responsabilité de la socialisation lorsque débute le baby-boom d'après la Deuxième Guerre mondiale.

\section{"He who sees things from their beginnings will have the finest view of them." - Aristotle}

One never has to delve very deeply into the literature on childrearing in Canada or the United States from the 1920s through the 1950 s to find the hand of Rockefeller philanthropy supporting individuals or organizations involved in the production or dissemination of child-rearing knowledge, especially the Laura Spelman Rockefeller Memorial Fund (LSRM). Mona Gleason, for example, frequently noted the funding role of the LSRM in her Normalizing the Ideal: Psychology, Schooling, and the Family in Postwar 
Canada. However, she made little of the source of funds for Canadian psychologists and psychiatrists such as William Blatz and Samuel Laycock. ${ }^{P}$ Indeed, Canadian and American educational historians regularly note the incidence of Rockefeller philanthropic support for the principal opinion-leaders of psychological and educational circles but seldom consider the significance of this common source of funds in relation to the ubiquitous approach to child-rearing tendered by those of influence, nor its relationship to other programs funded by the philanthropy. ${ }^{2}$

In this article, I argue that Rockefeller philanthropy fundamentally controlled psychological discourse concerning childrearing and pedagogical practices in post-World War II Canada and the United States. The philanthropy's officers were, in essence, funding support for a particular psychological approach to matters concerning children so extensively and effectively that they in effect shaped the consensus for the "modern" child-rearing philosophy typified by Blatz and Laycock in Canada and Arnold Gesell and Benjamin Spock in the United States. Philanthropic funding supported the proponents of "mental hygiene," providing them with institutional bases to legitimate their ideals of child rearing, and forums to present these, while marginalizing alternate ideals and alternate research into parenting and pedagogical practices by lack of funding. As a result, literature of the post-World War II period gives the appearance of almost universal expert support for "modern" child-rearing methods when, in truth, it reflects almost universal authority over child-rearing expertise by Rockefeller philanthropy.

Overlapping this interest in family and school, communications research likewise became a funding priority for Rockefeller philanthropy in the 1930s. At the same time as Rockefeller-supported hygienists were attempting to guide the psychological and social development of children through their parents and teachers, Rockefeller-funded programs in communications were emerging which, as media historian William J. Buxton has noted, assumed as their primary concern, "how minds were reached - and controlled externally, through the intricate web of communications." 3 Thus, of the four key domains in the socializing matrix for children - family,

1 Mona Gleason, Normalizing the Ideal: Psychology, Schooling, and the Family in Postwar Canada (Toronto: University of Toronto Press, 1999).

2 For an exception, see Steven L. Schlossman, "Philanthropy and the Gospel of Child Development," History of Education Quarterly 21 (Fall 1981): 275-99.

3 William J. Buxton, "The Emergence of the Humanities Division's Programs in Communications, 1930-1936," Research Reports from the Rockefeller Archive Center 1, 1 (Spring 1996): 4. 
school, media, and peer group - all but the latter group were of interest to Rockefeller philanthropy, a condition that makes it pertinent to examine the role played by the philanthropy in the origins and development of the mental hygiene movement and mass communications research conjointly, as well as individually, in assessing the involvement of the philanthropy in the post-World War II socialization of American and Canadian children.

\section{Rockefeller Philanthropy and the Mental Hygiene Movement}

The Rockefeller Foundation (RF) did not conceive the mental hygiene movement, of course, nor was the RF present at its birth in the United States in 1909; but the foundation took an interest in the movement in its infancy, once issues of leadership and direction of the National Committee for Mental Hygiene (NCMH) had been resolved to its satisfaction. Following an internal struggle within the $\mathrm{NCMH}$, the American psychiatrist, Adolf Meyer, took up the leadership of the nascent committee from its founder, Clifford Beers, and redirected the focus of the $\mathrm{NCMH}$ from its initial concern for the institutional care of the insane to the application of psychiatric principles to the improvement of society. Then, according to Theresa Richardson, the RF "essentially adopted the National Committee for Mental Hygiene."

Meyer's work - "dynamic psychiatry," or what he characterized as a "psychobiological approach to mental disease" - emphasized the ways in which the attitudes of individuals were conditioned by the different groups to which they belonged. ${ }^{5}$ He stressed the role of the family, school, peers, workplace, and community - in short, the social environment - in the socialization of the individual, with the parentchild relationship deemed to be of primary importance in this regard.

4 Theresa R. Richardson, The Century of the Child: The Mental Hygiene Movement and Social Policy in the United States and Canada (New York: SUNY, 1989), 55.

5 Dynamic psychiatry broadened the scope of psychiatry to include the personal, psychological, and social experiences influencing personality development, a comprehensive view that constituted a major departure from the psychoanalytical approaches that had preceded it. Meyer's psychobiological model of personality formation made use of the concept of habit to bridge the organic and psychical aspects of an individual. He argued that the cumulative effect of early faulty habit patterns produced abnormal behaviours in later life. For a succinct but comprehensive discussion of Meyer's work and life see Ruth Leys and Rand B. Evans, eds., Defining American Psychology: The Correspondence between Adolf Meyer and Edward Bradford Titchener (Baltimore: The John Hopkins University Press, 1990). As a primary source for the writings of Meyer see Alfred Lief, ed., The Commonsense Psychiatry of Dr. Adolf Meyer: Fifty-two Selected Papers (New York: McGraw-Hill Book Co., 1948). 
Through the repeated interactions between parent and child, he theorized, children internalized the norms and values of their family, and built up emotional attitudes and predispositions that constituted their personality. RF funding for the reconstituted NCMH brought its work to the foreground among American and Canadian psychiatrists, psychologists, and educational leaders. In due course, modifying family and school adult-child interactions would become the primary goal of philanthropically supported projects related to child-guidance, parent-education, and school reform. ${ }^{6}$

As with the conception of the NCMH, the RF was not on hand for the birth in 1918 of the Canadian National Committee for Mental Hygiene (CNCMH). By 1920, however, negotiations were under way between Clarence Hincks - then secretary of the CNCMH - and Edwin R. Embee, George E. Vincent, Beardsley Ruml, and Lawrence K. Frank of the LSRM for their support of the psychological research program of the Canadian Committee. Clifford Beers, who was by that time merely a figurehead for the $\mathrm{NCMH}$, attempted to dissuade Hincks from forming a dependency on Rockefeller philanthropy, but without success. By accepting Rockefeller funding beginning in 1924, the $\mathrm{CNCMH}$ inadvertently departed from an indisputably independent research path to become a Canadian cousin to the $\mathrm{NCMH}^{7}$

As Rockefeller philanthropy fostered it, mental hygiene was a design for improving future society by altering the psychological conditions of childhood within families, schools, and communities. The changes that were to be promoted within these structures were derived from a loose cluster of notions concerning children collected from a number of "enlightened" sources - Meyer, Jean-Jacques Rousseau, Friedrich Froebel, G. Stanley Hall, Ellen Key, and Sigmund

$6 \quad$ Leys and Evans, Defining American Psychology, 53-54.

7 Before 1924, private benefactors including Lady Eaton, Lord Shaughnessy, Vincent Massey, and Robert Falconer, president of the University of Toronto, were the major patrons of the CNCMH. Several initial differences existed between the CNCMH and the NCMH. For one, the CNCMH was an umbrella organization that supported the eugenics movement and intelligence testing, as well as mass personality development. For another, the CNCMH continued to be guided by Clifford Beers toward the improvement of facilities for the mentally ill, long after he had been maneuvred into a figurehead role by the American committee. For more information on the formation of the CNCMH see Angus Mclaren, Our Own Master Race: Eugenics in Canada, 1885-1945 (Toronto: McClelland and Stewart, 1990) as well as Richardson, The Century of the Child. A discussion illustrating how Rockefeller philanthropy could control a foreign "independent" agency such as the CNCMH can be found in Stephen P. Turner, "Does Funding Produce Its Effects? The Rockefeller Case," in The Development of the Social Sciences in the United States and Canada: The Role of Philanthropy, ed. Theresa Richardson and Donald Fisher (Stamford, Connecticut: Ablex, 1999), 213-26. 
Freud being the most prominent - which were cemented into a unified "scientific" approach to child-rearing and schooling. Although the approach was at variance with the common-sense practices of the majority of North American parents and teachers of the time, the principles of mental hygiene were propelled into a place of prominence in the consciousness of North American society by Rockefeller funding (along with its sister philanthropy, the Commonwealth Fund), promoted alternately as the "modern" or "democratic" or "scientific" method of child-rearing and teaching. ${ }^{8}$

The intent in American public schools was to make teachers less rigid, moralistic, punitive, and authoritarian and to make students happier in school, more successful, and, above all else, more sociable. As hygienist William Healey wrote in a 1933 article in the Journal of Educational Sociology, the primary question was not "What does the child learn in school?" but rather, "How does the child feel because of school?", Similar notions were later advanced into Canadian schools by experts such as John D. Griffin of the Canadian Mental Health Association (a 1934 Rockefeller Fellowship recipient), Samuel Laycock, and William Line (all colleagues in the RF- and LSRMfunded $\mathrm{CNCMH}$ ), who likewise extolled the possibilities of building in students sound emotional habits, strong personalities, and good social relationships through less-authoritarian teaching practices and greater emphasis on satisfying children's needs for belonging, social approval, and self-esteem. ${ }^{10}$

8 The Commonwealth Fund was established in 1918 by the wife of Stephen Harkness, an early partner of John D. Rockefeller, Sr., in Standard Oil. A comprehensive list of funded institutions and projects for the mental hygiene movement has yet to be compiled. However, a partial list for Canada can be found in the Canadian Mental Health Association's Milestones in Mental Health: A Record of Achievements, 1918-1958 (Toronto, National Office of The Canadian Mental Health Association, 1959), as well as in Gleason, Normalizing the Ideal. For the United States, the best sources of information about the mental hygiene campaign are to be found in various articles by Sol Cohen and Steven L. Schlossman. To begin reading in the field, see Sol Cohen, "The Mental Hygiene Movement, the Development of the Personality and the School: The Medicalization of American Education," History of Education Quarterly 23 (1983): 12349, as well as Schlossman, "Philanthropy and the Gospel of Child Development."

9 William Healy, quoted in Sol Cohen, "The Mental Hygiene Movement, The Commonwealth Fund, and Public Education, 1921-1933,” in Private Philanthropy and Public Elementary and Secondary Education: Proceedings of the Rockefeller Archive Center Conference held on June 8, 1979, ed. Gerald Benjamin (New York: Rockefeller Archive Center, 1980), 46.

10 See Gleason, "Psychology in Postwar Schools," in Normalizing the Ideal. For more information on John Griffin's Rockefeller connections see Joe Blom Djuwe and Sam Sussman, Pioneers of Mental Health and Social Change, 1930-1989 (London, Ont.: Third Eye, 1989), 43. 
The primary goal of the RF and LSRM parent education campaign was similar to the therapeutic aim in the public schools: to decrease the domineering and autocratic practices of parents and thus advance the development of each child's personality. Steven Schlossman traces the origins of the modern parent education movement to the LSRM and to its senior officer, Lawrence K. Frank, a champion of progressive educational ideas generally and an advocate for the hygienist perspective on child-rearing in particular. ${ }^{11}$ Commencing in 1923, Frank administered one million dollars annually for the LSRM, a fund by which he subtly but aggressively nurtured and co-ordinated the parent education project. The most notable outcome of the project was Parents' Magazine, a popular monthly discreetly funded by the LSRM through Teachers College at Columbia University - as well as through Yale, Minnesota, and Iowa Universities - which "soon became the largest selling educational periodical in the world." "12

The research basis for the mental hygiene approach to schooling was tenuous at best. As Sol Cohen has mused: "Who could have known how flimsy the foundation on which the program was erected would, with the benefit of hindsight, turn out to be?"13 Cohen locates the underpinnings of the American movement in Meyer's notions of dynamic psychiatry bolstered by Freudian theory - that is, based in theory rather than on empirical research. ${ }^{14}$ As Hans Pols observes of the $\mathrm{CNCMH}$, the Canadian program had established a distinct empirical research program at the outset of its funding by the RF and LSRM, but over the years of its association with its American counterpart the institution was drawn more and more in line with the NCMH. ${ }^{15}$

11 Schlossman, "Philanthropy and the Gospel of Child Development,” 279.

Ibid., 294.

Cohen, "The Mental Hygiene Movement, the Commonwealth Fund, and Public Education," 44.

14 Sol Cohen, "The Mental Hygiene Movement, the Commonwealth Fund, and Education, 1921-1933: 'Every School a Clinic,'” in his Challenging Orthodoxies: Toward a New Cultural History of Education (New York: Peter Lang, 1999), 187.

15 Hans Pols, "The World as Laboratory: Research Developed by Mental Hygiene Psychologists in Toronto, 1920-1940," in The Development of the Social Sciences in the United States and Canada: The Role of Philanthropy, ed. Theresa Richardson and Donald Fisher (Stamford, Connecticut: Ablex, 1999), 115-42. 


\section{Rockefeller Philanthropy and Arnold Gesell}

By the end of the 1920s LSRM and RF grants were funding child-study clinics at Iowa, Columbia, Berkeley, Toronto (where Blatz was employed), and Minnesota Universities - but it was at Yale University, the bastion of the mental hygiene movement since 1909, that the monographic equivalent to Parents' Magazine was ultimately produced. There, at the "Yale School of Medicine, Clinic of Child Development," under the direction of Arnold Gesell, emerged the landmark child-rearing text by Drs. Gesell and Frances Ilg, Infant and Child in the Culture of Today (1943). Their work gave the stamp of scientific certitude to the long-held hygienist assumption that social development, like physical development, passed through "normal and natural stages," which "too often parents lacking in knowledge of child development will punish their children for."

The long and patient study of child behavior made by Dr. Gesell and other workers in the field has made it clear that childhood's greatest need from birth throughout the formative years is for a parental attitude of enlightened understanding. For this understanding with love and care will bring to healthy fruition the budding individuality of the citizen of tomorrow's world. ${ }^{16}$

In his foreword for Infant and Child in the Culture of Today, Gesell acknowledged the substantial funding of the clinic by the RF: "We are fundamentally indebted to the Rockefeller Foundation, which over a period of years has given generous long range support to systematic investigations which underlie the present work." "To judge from Life with Baby (1946), a Time/Life documentary film depicting the work of the clinic, although the long and patient study of Dr. Gesell made evident that children passed through "natural stages of physical and mental growth," it did not, as was claimed in the film, likewise prove that children passed "socially through observable normal patterns." Blurring the distinction between natural growth processes and social

16 Soundtrack from Life with Baby, 18min., 16mm, sound, b\&w film, Time/Life, New York, 1946. As Donald Fisher observes, "By the turn of the century, 'science' and 'scientist' had become the most legitimate knowledge labels in North American society. During this century, the primary route for increasing the power and raising the status of knowledge has been to make it scientific." See his Fundamental Development of the Social Sciences: Rockefeller Philanthropy and the United States Social Science Research Council (Ann Arbor: University of Michigan Press 1993), 14.

17 Arnold Gesell, Frances Ilg, inter alia, Infant and Child in the Culture of Today: The Guidance of Development in Home and Nursery School (New York: Harper and Brothers, 1943), xi. 
learning processes appears to have been an attempt by the filmmakers to foster mental hygiene child-rearing patterns in post-World War II American homes:

Parents punish their four-year-old child for making faces at people. Fortunately, parents who understand the normal stages of growth do not punish the child for behaving like this. They are better able to guide him and enjoy him because they know that many troublesome phases are simply normal and natural stages in the child's development. ${ }^{18}$

The National Film Board of Canada (NFB) drew heavily from Gesell and Ilg's work for its Ages and Stages Series (1949-1954) of parenting films. ${ }^{19}$ Indeed, the title of the award-winning series was adapted from a chapter of Infant and Child in the Culture of Today; and in one film, He Acts His Age (1949), a child-rearing expert opens the clinicians' second book, The Child from Five to Ten (1946), for reference. In another 1946 NFB documentary, What's on Your Mind?, William Blatz, the director of the Rockefeller-funded Institute of Child Study at the University of Toronto, states the hygienist case succinctly:

Nervous breakdowns come pretty late, but they always come after a very poor young childhood. Now, we know there are certain things in childhood that will make for a nervous breakdown later on... [One] thing is nagging, and I'm afraid mothers nag more than fathers, Mrs. Madge. Nagging, I think, is the worse crime in the parental calendar. ${ }^{20}$

In regard to Meyer's psychobiological model of personality development, perhaps the most significant change to child-rearing literature brought about by Rockefeller funding of Arnold Gesell's work was the substitution of a fixed feeding schedule with "selfdemand feeding." Applying the rationale of Meyer's model, such a change would shift - at the very outset of the mother-child relationship - the initial power balance between parent and child. As

18 Soundtrack from Life with Baby.

19 See Brian J. Low, NFB Kids: Portrayals of Children by the National Film Board of Canada, 1939-1989 (Waterloo: Wilfrid Laurier University Press, 2002) for more details concerning this series and other NFB productions containing child-rearing information.

20 Soundtrack from What's On Your Mind?, 10 min., 16mm, sound, b\&w film, National Film Board of Canada, Montreal, Canada, 1946. Laycock, unlike Blatz, never appeared in a NFB production. 
Gesell saw it, since it entailed the symbolic first struggle of wills between the mother and her child, "the [feeding] schedule thus becomes at once symbol and a vehicle of cultural control."21

Earlier, in his Feeding Behavior of Infants: A Pediatric Approach to the Mental Hygiene of Early Life, Gesell had extolled the mental health benefits of the self-demand schedule of feeding. While conceding that "the psychology of infant personality is terra incognita," Gesell argued, "it would...seem wiser to give the infant the lead in initiating variations from day to day because through these variations he tests and achieves his powers... which should be respected in the interest of his mental hygiene." 22 In contrast, Gesell warned, "If the constitutional indicators are ignored in the interest of an inflexible schedule, there ensues a contest between infant and adult... waged with unnecessary losses and emotional disturbances on both sides."23 For a mother to avoid creating emotional conflict, Gesell advised, "This demand for the shorter interval should be respected. Instead of making a fetish of regularity, it is wiser to accede to his special demand." 24 In so doing, Gesell assured a reader, "The infant is most directly and most completely satisfied... The promptness and certainty of satisfaction cumulatively experienced - there are over 2,000 feedings in the course of the first year - will nourish that sense of security which is essential to mental health." ${ }^{25}$ Gesell proposed that, in this matter and other early interactions between parent and child, "Judicious allowances will be made by [a liberal and democratic] parent and there will be a conscious and subconscious tendency to arrive at the infant's 'point of view.' 'This understanding attitude will color the adult-infant relationship beneficially." ${ }^{26}$

Finally, Gesell offered this aside:

Here lies the most promising field for medical guidance. In almost a literal sense, the physician can reach the mind of the infant by altering undesirable attitudes in the parent...He may even have to take into account the attitude of grandmother or other adults in the household. All of this can be done on medical grounds, because of its direct bearing on the hygiene of the

21 Gesell et al., Infant and Child in the Culture of Today, 48.

22 Arnold Gesell and Frances L. Ilg, Feeding Behavior of Infants: A Pediatric Approach to the Mental Hygiene of Early Life (Philadelphia: J.B. Lippincott Co., 1937), 100.

23 Ibid., 107.

24 Ibid., 102.

25 Ibid., 107

26 Ibid., 133. 
infant's feeding and of related behavior. The physician does not step out of his role when he consciously addresses himself to the adult-infant relationship as a dynamic reality which yields to advisory control. ${ }^{27}$

Thus, Feeding Behavior of Infants was written almost exclusively for medical professionals - especially pediatricians and general practitioners. In his acknowledgements, Gesell thanked two Rockefeller philanthropies: "The present and associated researches were made possible through grants of the General Education Board and The Rockefeller Foundation. We wish to make special acknowledgement of the generosity and scientific stimulus of these grants." 28

In truth, Gesell's supposition that self-demand feeding nourished a sense of security that would lead to better mental health was as scientific as mind-reading. There was no empirical evidence to support what he supposed an infant was thinking and learning during feeding, nor any longitudinal studies that demonstrated that the selfdemand model would ultimately benefit a child's mental health. ${ }^{29}$ Gesell was simply applying established mental hygiene precepts to infant feeding. Differing, but equally plausible hypotheses, could have been generated concerning what predispositions an infant would develop during a possible two thousand self-demand feedings and what the outcome would be to his or her mental health - but mental hygiene was the theory universally advanced by child study experts and organizations that received Rockefeller funding. Raised to the level of sound medical advice through Gesell's work, self-demand feeding extended the hygienists' aim of reducing parents' and teachers' authority over the socialization of children into the very cradle of adult-child social relationships, while leaving untouched children's peer relationships and the socializing power of the media.

\footnotetext{
27 Ibid., 135.

28 Ibid., v.

29 It was not until the early 1970s that credible empirical studies were made of infant and mother social relations. As the American psychiatrist, Daniel N. Stern, noted, "It became necessary to re-conceive the units of discourse. Units such as intrusiveness, sensitivity, and rejection were too large, too global, too vague... The new behavioral units became gaze aversions, head turns, speed of physical approach, duration of a facial expression, small shifts in arousal, and so on." See The First Relationship: Infant and Mother (Cambridge, Mass.: Harvard University Press, [1977]), 3.
} 


\section{Parents' Magazine and the Self-demand Feeding Concept}

Following the progress of Gesell's self-demand feeding concept within Parents' Magazine illuminates the authority that Rockefeller philanthropy held over child-rearing advice. ${ }^{30}$ In 1937, when his Feeding Behavior of Infants first appeared in print, articles concerning infant feeding in the magazine consistently advocated scheduled feedings. Indeed, in one article, "A Schedule for the New Mother," its author unintentionally contradicted Gesell's opinion about feeding schedules and feelings of security in a baby: "The thing that most distinguishes the modern baby from his old-fashioned counterpart is that the former has a schedule. He is healthier because he is trained to eat, sleep, and exercise regularly. This helps him to perform all of his bodily functions with equal regularity. He is happier and better behaved, because once he becomes accustomed to his schedule, he finds therein a certain sense of security." The writer, who suggested that mothers should adopt a three-hour rather than a four-hour feeding schedule, cautioned that any schedule should be followed as a guide, not as a rigid rule, that "[the] schedule is subject to her discretion. It should be revised by her to suit her convenience." 31 Other contributors to Parents' Magazine that year echoed her counsel. One author suggested moving a feeding time forward or backward from one hour to the next "by varying each feeding five minutes in the direction which you wish to make the change until you arrive at your destination." 32 Whether advising mothers to hold to a schedule or to vary it for convenience, no contributor to Parents' Magazine in 1937 advocated that the feeding schedule should be left to the discretion of the child, rather than the mother or her doctor.

During the next five years, the subject of infant feeding schedules appeared infrequently in the monthly magazine, occasionally referred to peripherally in articles critical of "super-efficiency schedules," which, according to contributors, made motherhood as impersonal as office work, when "duties could so easily be turned into pleasures." 33 In 1940, for example, an argument was made by a contributor,

30 Steven Schlossman observed that the financial arrangement between the LSRM and Parents' Magazine “was extraordinarily complex and roundabout; it reflected LSRM's decision not to be publicly identified or officially connected to the periodical, and to rely on its beneficiaries in the parent education movement to exercise quality control." Schlossman, "Philanthropy and the Gospel of Child Development," 293-94.

31 Billie Wyer, "A Schedule for the New Mother," Parents' Magazine XII, 2 (1937): 22.

32 Marion LeBron, “Making Baby Care Easy,” Parents’ Magazine XII, 4 (1937): 29.

33 Wilma Margaret Clem, “Enjoy Your Baby,” Parents' Magazine XIV, 4 (1939): 22. 
formerly a businesswoman, that mothers should strive less for office efficiency and attend more to obtaining enjoyment from their babies - but even she conceded of her child's four-hour feeding schedule: "I followed this schedule literally to the minute, and I found it an excellent one. I have no quarrel with teaching a baby good habits and routine. Any normal, healthy baby will respond beautifully and be much less trouble to its mother." 34

In 1942, however, following a five-year hiatus in practical advice about feeding schedules, an article titled, "Let's Feed Babies when They're Hungry," by Lucia Manley Hymes, abruptly brought the hygienist case for self-demand feeding to the fore. Hymes argued that all the time a baby was an embryo it received all it wanted to eat, but "[now] in the world at last... all the baby knows is that if he develops an appetite half an hour before the clock says it is mealtime, he can cry it out." Hymes advised readers that one of the surest ways to produce a "finicky" eater "is to ignore the child's own hunger demands and to impose your own ideas upon him." Further, Hymes wrote, "It cannot be repeated too often that a baby is learning something all the time. If his legitimate wants are ignored, he may be learning that this is a hostile world, and he may be building up ideas that later on will make him an angry, difficult child." 35 With her own baby, the author revealed, she had tried "self-demand" feeding and was "soon convinced that [her daughter] knew better than us what was good for her." Moreover, Hymes observed, "The beauty of this system was that she was peaceful and I was peaceful and we both enjoyed each other tremendously." addressed a counter-argument "most frequently raised against such a flexible program...that it will spoil the child."

Parents fear that if they let the child dictate to them in the manner above indicated he will become more and more demanding of attention, that he will want his slightest whim gratified at a moment's notice. However, Dr. Gesell of the Yale Clinic found just the opposite to be true. He says, "By meeting the infant's demands promptly he is most directly and most completely satisfied. He escapes periods of want, anxiety and distress. The promptness and the certainty of satisfaction

34 Martha Holton, “How Efficient Should a Mother Be?” Parents' Magazine XV, 7 (1940): 20.

35 Lucia Manley Hymes, “Let's Feed Babies When They're Hungry,” Parents' Magazine XVII, 4 (1942): 24.

36 Ibid., 25. 
cumulatively experienced - there are over 2,000 feedings in the course of the first year - will nourish that sense of security which is essential to mental health. ${ }^{37}$

Gesell had not "found" any such thing "to be true," of course. It was merely an opinion based upon mental hygiene theory. With this epistemological smudging, however, a Rockefeller-funded notion was now transmitted as medical knowledge to an audience composed mostly of new parents through a Rockefeller-funded medium that was now coming into line with the mainstream of Rockefeller-fostered mental hygiene thinking.

After Hymes' April 1942 article, there was a steady shift in advice tendered by the magazine in favor of self-demand feeding. Four months after publishing "Let's Feed Babies When They're Hungry," the magazine printed "Off to a Good Start in Baby Feeding," which opened with this recommendation: "Babies cry when they have hunger pangs, and it has been found that these hunger pangs come at fairly regular intervals and should be considered in planning feeding schedules." "38 Less than a year later, in June 1943, the advice was less tentative: "The specific lesson here is that mothers should make sure that their babies' schedules for feedings are adapted to the needs of the individual baby and that the baby is not made to adjust whether he likes it or not to a fixed schedule." 39 By 1945, feeding schedules were already being referred to as a thing from the distant past, as in the article, "New Ways with a New Baby," which began, "Praise Heaven our new baby was not born into the old-fashioned baby care world of the twenties and thirties - into the rigid, 6-10-2, let him cry it out, 20 minutes per feeding era of child care." ${ }^{40}$ By the end of 1945 , an article entitled, "He Knows when He's Hungry," and the caption below it, made further reading of the article unnecessary: "Babies are happier these days when feeding schedules follow their appetites rather than the clock." 41

By 1946, at the outset of the post-World War II "baby boom," infant feeding advice offered in Parents' Magazine called, in the main,

37 Arnold Gesell, cited in Hymes, “Let’s Feed Babies When They’re Hungry,” 111. 38 Elizabeth L. Schweiger, “Off to a Good Start in Baby Feeding," Parents' Magazine XVII, 8 (1942): 22. In an unusual move, the magazine inserted this qualifier beneath Schweiger's name: "This article was read and approved by a well-known pediatrician." 39 Louise P. Woodcock, "Personality in the Making," Parents' Magazine XVIII, 6 (1943): 24.

40 Rosalind Bacon Hall, “New Ways with a New Baby,” Parents' Magazine XX, 9 (1945): 18.

41 Mary D. Moore Vance, “He Knows when He’s Hungry,” Parents’ Magazine XX, 12 (1945): 25. 
for absolute self-demand feeding. In "New Knowledge about Babies" the contributor declared, "A baby should be fed all he wants to eat, when he wants it. He should have ample opportunity to suck between times if he displays a need in that direction." 42 In "SelfDemand Babies," the article was captioned, "Do you generally know what you want? Well, so does your baby. And he's apt to be right, too." ${ }^{43}$ By 1947, ten years after the release of Gesell's Feeding Behavior of Infants, infant feeding advice offered in the magazine had settled into a range of advice between flexible schedules based upon a child's needs and unlimited self-demand feeding. In the June 1947 article, "Enjoy Your Baby," the author urged, "keep to a schedule as the weeks and months go by, but make it fit the needs of the baby rather than the other way around." ${ }^{\prime 4}$ However, in the July 1947 issue, Margaret H. Bacon boldly titled her article, "Spoil that Baby!" and she meant it. ${ }^{45}$

Of all the contributors to Parents' Magazine who applied mental hygiene principles to their child-rearing advice, none benefited more from their exposure in the magazine than Dr. Benjamin Spock. ${ }^{46}$ Spock - who had undergone his early medical training in the mid1920s at Yale University and his pediatric training through the early 1930s at Columbia University, during RF and Commonwealth Fund campaigns for mental hygiene at both institutions - first came to national attention in the monthly periodical in 1945. By the time his Common Sense Book of Baby and Child Care (1946) was published, four articles derived from the book had already been printed in four consecutive issues of Parents' Magazine, from March to June 1945. Furthermore, notice of the book's forthcoming publication was inserted within each article (an unusual advertising practice for the magazine), bestowing upon Spock a huge advantage in the childrearing advice market at the outset of the "baby boom." Spock had received no direct funding from the philanthropy and had no need to acknowledge Rockefeller support for his Common Sense Book of Baby

42 Evelyn Emig Mellon, “New Knowledge About Babies,” Parents’ Magazine XXI, 8 (1946): 120.

43 Dorothy V. Whipple, M.D., “Self-Demand Babies,” Parents’ Magazine XXI, 12 (1946): 20.

44 Helen Chrostowski, “Enjoy Your Baby,” Parents’ Magazine XXII, 6 (1947): 103.

45 Margaret H. Bacon, “Spoil that Baby!” Parents’ Magazine XXII, 7 (1947): 20.

46 Spock's opening stand on the feeding schedule debate set him firmly in the selfdemand camp, but not explicitly so: "I don’t think myself it's very important whether a baby is fed purely according to his own demand or whether the mother is working toward a regular schedule - if she is willing to be flexible and adjust to the baby's needs and happiness.” Benjamin Spock, The Pocket Book of Baby and Child Care_(New York: Pocket Books, 1946), 30. 
and Child Care; yet to a large extent, he owed both the temper of its advice and its pre-publication publicity to the fundamental authority exercised by Rockefeller philanthropies over earlier individuals and institutions charged with producing and disseminating child-rearing knowledge - a debt that was more than paid for when mental hygiene principles became reified in his book as "common sense."

\section{The Canadian Context}

How extensive was Rockefeller control over post-World War II child-rearing expertise in Canada? By 1950, the RF and LSRM fundamentals of "modern" child-rearing were being disseminated exclusively over every mass medium in Canada, including CBC Radio and the National Film Board of Canada; ${ }^{47}$ they were the guiding principles of every popular Canadian child-rearing "expert" including Blatz, Griffin, Laycock, and Line - and likely of family doctors as well; ${ }^{48}$ they formed the very foundation of Dr. Spock's approach to child guidance, ${ }^{49}$ they informed Canadian readers of Chatelaine and Maclean's magazines, as well as Parents' Magazine; and they had penetrated Canadian medical periodicals such as the Canadian Medical Association Journal and Health: Canada's Health Magarine, and, likewise, post-World War II editions of popular Canadian pediatric works, such as Canadian Mother and Child by Dr. Ernest Couture. ${ }^{50}$ Mental hygiene concepts were pervasive in Canadian educational

47 Samuel Laycock was a regular contributor on CBC Radio as host of the "School for Parents" program. He and Blatz were also regular contributors to Parents' Magazine, for which both men won prizes. The Ages and Stages series of films on parenting produced by the NFB of Canada from 1949 to 1954 were adapted from Gesell and Ilg's Infant and Child in the Culture of Today.

48 As Gleason demonstrates in Normalizing the Ideal, articles with a psychological slant on child-rearing came to dominate 1950s medical periodicals such as the Canadian Medical Association Journal and Health: Canada's Health Magazine, as well as more widely popular magazines, such as Maclean's and Chatelaine.

49 Typical of mental hygienist psychological advice for parents and teachers to be found in The Common Sense Book of Baby and Child Care (1946) are passages such as "What makes your child behave well is not threats or punishment but loving you for your agreeableness" and, in the "Schools" subsection of the work, "[A] good teacher...knows that she can't teach democracy out of a book if she's acting like a dictator in person." Spock, Pocket Book of Baby and Child Care, 260, 314.

50 The most notable change brought about in the advice offered in The Canadian Mother and Child was from the counsel to mothers in the 1940s edition to instigate a feeding schedule immediately after birth, to the advice offered in the 1953 edition suggesting that mothers self-demand feed a baby at first. See Ernest Couture, M.D., The Canadian Mother and Child (Ottawa: Child and Maternal Hygiene Division, Ministry of Pensions and National Health, 1940), 108-11; and The Canadian Mother and Child (Ottawa: Department of National Health and Welfare, 1953), 75-76. 
documents by the mid-1940s - even though, as George S. Tomkins observed in A Common Countenance: Stability and Change in the Canadian Curriculum, "It would appear...that mental hygiene and related innovations were foisted on an often resistant school system as a result of outside establishment pressure." ${ }^{51}$ They appeared in early 1950s NFB teacher training films, such as Shyness (1953), in which social and emotional difficulties at school were attributed to overprotective and demanding mothers, and they were explained to Canadian television audiences in the mid-1950s in CBC television programs about schooling, such as Child Guidance Clinic, in which a Toronto school principal, articulating the goals of his elementary school, echoed the aims of the American Progressive Education Association following its adoption of the agenda of the $\mathrm{NCMH}$ in the 1920s: "The school no longer regards it as its main function to simply teach academic skills. Educators are now interested in the child acquiring habits and attitudes that will make him a happy child, a more successful student, and a better and more useful citizen." 52

Among the educational establishment, there was little resistance to this incursion into Canadian socializing structures - outside of Hilda Neatby, who wrote in So Little for the Mind with typical acerbity toward mental hygiene that "no adult mind could possibly take it seriously." "53 But despite her critique, no counter-hegemony developed among Canadian child psychologists or psychiatrists (although prior perspectives, such as Couture's, Helen MacMurchy's, or Alan Brown's, were available for defending ${ }^{54}$ ); nor were opposing

51 George S. Tomkins, A Common Countenance: Stability and Change in the Canadian Curriculum (Scarborough, Ont.: Prentice-Hall, 1986), 178.

52 Soundtrack from Child Guidance Clinic, 28 min., 16mm, sound, b\&w film, National Film Board of Canada, Montreal, Canada, 1955.

53 Hilda Neatby, So Little for the Mind (Toronto: Clarke, Irwin Co, 1953), 351n33. A backlash against progressive educational ideas in general did develop within educational circles after the Russian launch of Sputnik in 1957. But this "back-to-thebasics" movement was shortly thereafter thwarted by the arrival of neo-progressivism onto the North American scene, which entrenched mental hygiene principles ever more deeply into the fabric of Canadian education. See R.D. Gidney, From Hope to Harris: The Reshaping of Ontario's Schools (Toronto: University of Toronto Press, 1999), as well as Tomkins, A Common Countenance, for comprehensive descriptions of educational change during the period.

54 Again, see Couture, The Canadian Mother and Child, as well as, earlier, Helen MacMurchy, M.D., The Canadian Mother's Book (Ottawa: Department of Health, 1923), and Alan Brown, M.B., The Normal Child: Its Care and Feeding (New York: The Century Company, 1923). For a comprehensive survey of Canadian child-rearing perspectives available during the first half of the twentieth century, see Katherine Arnup, Education for Motherhood: Advice for Mothers in Twentieth-Century Canada (Toronto: University of Toronto Press, 1994); Cynthia R. Comacchio, "Nations Are Built of Babies”: Saving Ontario's Mothers and Children, 1900-1940 (Montreal \& Kingston: McGill-Queen's University Press, 1993); Norah H. Lewis, “Advising the Parents: Child Rearing in British Columbia During the Inter-war Years” (D.Ed. diss., University of 
viewpoints published in popular Canadian periodicals - not because of a tendency by psychologists to "normalize the ideal," but because once the RF, the LSRM, and the General Education Board (GEB) had adopted the hygienist viewpoint as the governing ideal, no funding agency, private or public, supported any other. Plainly stated, Rockefeller philanthropy had cornered the market on child-rearing advice in both the United States and Canada. ${ }^{55}$

Why did agents of Rockefeller philanthropy hold so monolithic a view in child-rearing matters? As Richardson observed, "It was the possibility of shaping civilization which caught the imagination of Frederick Gates as he argued for the establishment of the Rockefeller Foundation." 56 To officers such as Frank, a more perfect social future lay with the child in the cradle, with "a growing belief in the possibility of directing and controlling social life through the care and nurture of children." 57 To a large extent, Frank reasoned, the social life of tomorrow was already determined by children of today. "The child," he wrote, "is the bridge - biologically and socially - to the future." 58 To engineer a bridge that would successfully transport "the child" to its intended destination required uniform building practices by those responsible for its construction - parents and teachers.

Why was mental hygiene employed by Rockefeller philanthropy as the blueprint for the bridge? At face value, it appears to have been an attempt to produce a mentally healthy adult society. Certainly, that

British Columbia, 1980); and the classic, Neil Sutherland, Children in English-Canadian Society: Framing the Twentieth-Century Consensus (1976; Waterloo: Wilfrid Laurier University Press, 2000 [new ed.]). One American psychiatrist who did take a stand against the rising tide of psychologized child-rearing was Hilde Bruch, in Don't Be Afraid of Your Child (New York: Farrar, Straus and Young, 1952).

55 As Stephen Turner points out in “Does Funding Produce Its Effects?” intermediary institutions such as the NCMH or CNCMH exercised caution in awarding RF grants and fellowships by choosing recipients whose aims and abilities were likely to match the goals of the Foundation. Or, as Hans Pols notes in "The World as Laboratory": "Organizations of the type of the NCMH are national in scope but usually far from national in origin of funds. In fact so narrow and definite is the source of support the executive secretaries must attend to foundation opinion with a constancy, shrewdness, and deference which is likely to belie the self assurance on each side that the committee's policies [are] entirely free from any foundation control. It becomes the secretary's job to guess what the foundations want...” (142). Judging from the ubiquitous tenor of North American expert child-rearing advice, all the beneficiaries of Rockefeller largesse presumed that the mental hygiene approach was what the philanthropy wanted.

56 Richardson, The Century of the Child, 37. According to Pols, the overall objective of Rockefeller philanthropy was "to bring the process of human evolution under intelligent control." Pols, "The World as Laboratory," 118.

57 Lawrence K. Frank, "Childhood and Youth,” in Recent Social Trends in the United States: Report of the President's Research Committee on Social Trends (New York: McGraw-Hill, 1933), 2: 753.

58 Ibid., 754, 800. 
was the rationale of the mental hygiene movement itself - to produce a generation happier, more productive, and more self-reliant than any previous generation, to "bring to healthy fruition the budding individuality of the citizen of tomorrow's world." 59 But this promised outcome was mere conjecture based upon mental hygiene theory. Employing the logic of the Meyer model, all that could be guaranteed if parents and teachers adopted the modern practices supported by Rockefeller philanthropy was that they would self-condition a reduction of their traditional control over the socialization of children. This was, after all, the very praxis of mental hygiene. As to the initial research results concerning the impact of mental hygiene practices on the mental health of children, these were almost certainly unanticipated and likely disconcerting.

\section{Early Mental Hygiene Research}

As Sol Cohen describes it in his article, "In the Name of the Prevention of Neurosis: Psychoanalysis and Education in Europe, 1905-1938," beginning in the early 1920s, a handful of psychoanalysts in Europe, including Anna Freud, "working independently, at different times, in different places, and with various degrees of eclecticism, attempted to demonstrate the practical corollaries of psychoanalytic doctrine for the education of children in school settings." 60 In every case, they tried to school the children in a permissive, "enlightened environment," sparing them the overly strict prohibitions and restrictions of the conventional schools of the time. Cohen records the results:

In comparison with children reared in the conventional way, these children appeared less inhibited, "but they were often less curious about the more complicated world of objects; they had no perseverance; and they easily relapsed into daydreaming." They clung to many infantile habits. Normal school life put a great strain on [them]; they were extremely intolerant of the demands of adults [and they] "showed an unexpected degree of irritability, a tendency to obsessions and depression, and anxiety." 61

59 Janet Learned, Yale Clinic of Child Development, soundtrack from Life with Baby. 60 In Challenging Orthodoxies: Toward a New Cultural History of Education, 166. 61 Ibid., 173 (omnibus paraphrase and quotations). It is interesting to note that the social critic Paul Goodman (1911-1972) observed that "chronic anxiety" in young people caused them to cling to "the one world-view" as represented by television as the only 
Ironically, when these children reached the period of latency, writes Cohen, "psychoanalysis had to be called in to deal with the threatened deterioration of character. In the end, the child psychoanalysts had to accept the pessimistic conclusions to which personal experience as well as educational experiment increasingly led." 62 As Anna Freud admitted in 1937, "After years of intensive work...we are certain only that there still exists no practicable psychoanalytical pedagogy." ${ }^{\circ 3}$

In fact, by at least the mid-1920s, Sigmund Freud's thinking had developed a contradictory path from whence it had begun; it became "anti-liberationist." In 1933, in his New Introductory Lectures on Psychoanalysis, Freud declared, "The child must learn to control his instincts...education must inhibit, forbid and suppress." ${ }^{64}$ In 1939, the RF and the LSRM ceased funding both the NCMH and the $\mathrm{CNCMH}$. According to Cohen, several European child psychoanalysts who were involved in the movement for psychoanalytic pedagogy, many in the United States by the 1940s, "now wrote criticisms of American progressive education for its overindulgence of children and its lack of structure and limits... They carefully detached psychoanalysis from permissive attitudes and practices in child rearing and education." 65

By the late 1940s, evidence of problems with modern childrearing had begun to appear in the family as well. In Canada, concerns with "democratic" parenting and schooling practices first became evident to a group of mental hygiene researchers working under the direction of John R. Seeley in the Toronto suburb of Forest Hill. $^{66}$ From 1949 to 1954, the University of Toronto and the $\mathrm{CNCMH}$, "to develop and use techniques for improving the mental health of an entire school population," jointly financed the "Forest

security. Goodman, quoted in Timothy Glander, Origins of Mass Communications Research During the American Cold War (Mahwah, New Jersey: Lawrence Erlbaum Associates, 2000), 181.

62 Cohen, "In the Name of the Prevention of Neurosis," 173.

63 Anna Freud, quoted in ibid., 174-76.

64 Sigmund Freud, quoted in ibid., 174-76.

65 Ibid.

66 The researchers were John R. Seeley, R. Alexander Sim, and Elizabeth W. Loosley. John Seeley's career is deserving of more careful scrutiny by Canadian social historians. He was involved in several projects on behalf of the mental hygiene movement in Canada, including Crestwood Heights and NFB film productions of the early 1950s. Less conspicuously, he received acknowledgement from David Riesman as a consultant for his landmark work, The Lonely Crowd (1950), which links Seeley to that bastion of the mental hygienists - Yale University - at a particularly heady time for the movement. 
Hill Village Project." ${ }^{67}$ Forest Hill families that adopted mental hygiene practices in the early post-war period had undergone significant changes by the early 1950s, appearing to investigators to be "a little like a country which, having operated under an authoritarian form of government has suddenly switched to a democratic form, without too much preparation for the change." 68 In theory and in practice in many Forest Hill homes, parents had followed expert child-rearing advice and endowed their children with considerable liberty for personal growth along with constant assurances of love and security. The objective in doing so was to bring about the early psychological emancipation of the children from their family. But in the process of emancipation, the researchers found, the families had developed some unforeseen problems.

A central problem observed by Seeley and his research team involved confusion over allocation of power among family members. Indeed, in some family circles, the authors noted, "the distinction between child and adult was by no means clear." Small children in particular, the investigators observed, were bewildered by the multitudinous choices of behaviour presented to them and many of them, consequently, became minor nuisances: "The old edict that 'a child should be seen and not heard' no longer holds in [Forest Hill]. Young children join in the conversation of their elders, frequently interrupting the talk of the grown-ups." ${ }^{69}$ In what was potentially a problem of larger proportions, older children generated worries for parents by employing their new-found liberty to play "kissing games." Parents in the community frequently complained to the researchers about this last trend, but felt powerless to reverse it, since they felt other children and other parents set the pace. Noted the investigators of the kissing games, "If this trend were fully generalized it would entail the collapse toward youth of the entire life experience."70

Most disquieting perhaps - considering this was a study by proponents of mental hygiene - an important piece of information was in effect buried in the endnotes to Crestwood Heights. In regard to the emotional well-being of children reared and schooled for mental health, the goal to which the Forest Hill Village Project was directed,

67 The Canadian Mental Health Association, Milestones in Mental Health: A Record of Achievements, 1918-1958 (Toronto, National Office of The Canadian Mental Health Association, 1959), 12. The CNCMH changed its name in 1950 to The Canadian Mental Health Association (during the same period that "mental hygiene" became "mental health.”).

68 John R. Seeley et al., Crestwood Heights (Toronto: University of Toronto Press, 1956), 167.

69 Ibid., 207.

70 Ibid., 70. 
Seeley wrote: "The only objective evidence on this point would seem to point towards no better mental health, or perhaps worse, among children in this community compared with some others elsewhere." Seeley revealed that Crestwood children ranked significantly worse in a normed psychological bank of tests in the following categories: "sense of personal freedom; feeling of belonging; freedom from withdrawing tendencies, and community relations." They ranked significantly better in no category at all. "This distribution," reported Seeley, "is almost the mirror image - i.e., reversal - of the community's picture of itself." " Despite this and other problems, Seeley and most of the researchers remained convinced of the benefits of the child-centred culture of Forest Hill (although they allowed that "given the nature of culture, any attempt to alter it raises the problem of an unanticipated result in the long term."72) However, at least one anonymous researcher sounded an alarm: "The rather unexpected and perhaps extraordinary spectacle presented by a community such as the one studied calls for a radical reconsideration of the whole enterprise of mental health education." 73 But no serious reconsideration of the enterprise was undertaken - not then, nor ever after. The die was cast; the triumph of the mental hygiene project had become self-sustaining.

\section{Post-World War II Entrenchment}

Throughout the first wave of the baby boom, Parents' Magazine maintained a strong mental hygiene perspective, essentially calling on parents to relax their control over their children's lives. In a 1947 article entitled, "A Child Should Be Free" (captioned "Every child needs the chance to explore on his own and to pick his friends free from parental supervision"), the author counselled, "The doting, the ever-ambitious, the too-protective parents must join the far-seeing

\footnotetext{
71 Ibid., 408, 491.

72 Ibid., 416. The researchers were assured primarily by the logic of the mental health approach to parenting. Children reared democratically would be less shackled in their progress toward autonomy and thus, on the whole, should logically live happier, more productive and independent lives than those raised by traditional, autocratic methods of parenting. If the logic seemed insufficient, they also offered the example of maturing Forest Hill adolescents, sixteen to nineteen years old, whose general pattern seemed to be one of acceptance of the adult values and way of life. What the researchers seemed to overlook in this example was that most Forest Hill adolescents of that age would have been born prior to 1940, and thus prior to the introduction of mental hygiene into Forest Hill.

73 Ibid., 410.
} 
parents in letting their children have as much freedom as possible." ${ }^{, 74}$ A similar sentiment was expressed in "The When, How and Why of Baby Care," in which the author counselled parents that "one of the first and most important things we all need to understand and always keep in mind is that a child is not a possession...he is our responsibility, he is not our chattel. We have been the instruments in creating him; nothing more." 75

As Cohen has observed of American textbooks and mental hygiene in the 1930s and 1940s, it was similarly the case that once the sensitive antennae of publishing firms saw which way the trend was moving in child-rearing advice literature, mental hygiene practices became the dominant-virtually ubiquitous - philosophy of published pediatricians as well. ${ }^{76}$ Moreover, during the greater part of the first two decades of American television broadcasting, "TV families" inadvertently embodied the psychological ideals of the parent education project. Lucy and Ricky Ricardo consulted Spock's Common Sense Book of Baby and Child Care in the popular I Love Lucy television series following the birth of "Little Ricky" in 1953, as did Rob and Laura Petrie while raising their son, Ritchie, on The Dick V an Dyke Show (1961-66). ${ }^{77}$ Ward and June Cleaver were model "enlightened" parents with their sons, Beaver and Wally, in the Leave It to Beaver series (1957-63), as were Jim and Margaret Anderson before them with their children in the Father Knows Best series (1954-63), and Danny and Kathy Williams with their offspring in the Make Room for Daddy series (1953-64). Unlike fictional families portrayed on television, however, for most North American families, neither the harmonious parent-child relationships of TV families nor those predicted by the mental hygienists were attainable ideals, regardless of whether they fashioned their child-rearing philosophy from a television model or followed the script for raising "well-adjusted" children written by the mental hygiene movement. ${ }^{9}$

During the same period in Canada, NFB "parents" of the time often projected hygienist attitudes when dealing with children.

74 G.M. Relyea, “A Child Should Be Free,” Parents’ Magazine XXII, 8 (1947): 30-31. 75 Jeanne Duplaix, “The When, How and Why of Baby Care,” Parents' Magazine XXIII, 1 (1948): 25.

76 Cohen, "The Mental Hygiene Movement, The Development of Personality and the School," 137.

77 Spock personally credited the I Love Lucy television series, which featured his book in more than one episode, for maintaining his dominance over the advice literature market during the 1950s. Benjamin Spock and Mary Morgan, Spock on Spock: A Memoir of Growing Up with the Century (New York: Pantheon Books, 1989), 137.

78 Again, see Gleason, Normalizing the Ideal, for a description of the picture of normality painted by post-World War II psychologists in Canada. 
Typical of NFB parent-child relations of the era was the production The Pony (1955). In the film, two farm children, a boy of eleven and his nine-year-old sister, are forbidden by their father to buy a horse. The children buy the pony anyway and hide it in an outbuilding until Christmas. When the pony whinnies, prematurely leading the parents to its stall, the parents speak sharply to each other, but they are not upset with the children. Instead, the father admires their insubordination: "They've certainly shown a lot of initiative." And when the surprise is revealed on Christmas morning, the mother remarks with pride, "To think the children did this all on their own."79 Even those who were by now far removed from the origins of mental hygiene had by the mid-1950s come to perceive it as the ideal - had "normalized the ideal," as Gleason sees it. The lament of a young mother from the 1957 NFB production, Popular Psychology, best illustrates the quandary faced by young parents of the era: "But we can't avoid psychology. It's like air!" 80 Like air, by the mid-1950s, the psychology of mental hygiene completely encircled American and Canadian parents and teachers, so successfully had the principles of the movement been disseminated by Rockefeller philanthropy.

Massive funding would have been required to reroute parents and teachers from the bridge that Rockefeller philanthropy had engineered, but no such funding was forthcoming - certainly not from the philanthropy itself. Rather, by the early 1930s, the various Rockefeller divisions were already taking steps to distance themselves from the movement. Pols suggests in his essay, "The World as Laboratory," that the RF abandoned mental hygiene agencies such as the NCMH and CNCMH in part because the Foundation had begun to redefine its mission in terms of the rhetoric of the natural sciences, had become reluctant to make use of intermediary organizations, and had lost its enthusiasm with projects aimed at fostering the mental health of whole school populations. ${ }^{81}$ In the wake of its enthusiasm, however, the RF, the LSRM, and the GEB had left behind an

\footnotetext{
79 Soundtrack from The Pony, 29 min., 16mm, sound, b\&w film, National Film Board of Canada, Montreal, Canada, 1955.

80 Soundtrack from Popular Psychology, 9 min., 16mm, sound, b\&w film, National Film Board of Canada, Montreal, Canada, 1957.

81 Pols, "The World as Laboratory," 136-37. This is not to say that Rockefeller philanthropy ceased to fund mental hygienists after the 1930s. Clearly Gesell was still receiving RF funding as late as 1946. Curiously, Pols also notes that one reason for funding intermediary organizations such as the NCMH and CNCMH in the first place was because the RF was wary of being involved in controversial issues and was thereby "protecting itself from claims of individuals and institutions."
} 
entrenched psychosociological system capable of destabilizing future society by altering the conditions of childhood present. ${ }^{82}$

Were post-World War II parents in Canada and the United States to apply the "scientific" methods en masse, in a single generation mental hygienists might achieve exactly that which they claimed to abhor - a society shaped by scientifically unsound child-rearing practices. The evidence suggested that if parents and teachers were to follow the hygienists' advice en bloc, the potential existed for a new generation to appear that would be more wilful in character, less inhibited, and more peer-cohesive than ever in the past, a generation lacking a sense of personal freedom and thus likely - as the American psychologist Hilde Bruch saw it in 1952 - to be "helpless prey to outer influences, insecure and dependent on others, like leaves in the wind." 83 As for future generations, no social theorists, certainly none funded by the philanthropy, appear to have calculated what would transpire beyond the envisioned "new generation"; none pondered, for example, whether a generation with a more wilful character would manage marriage as well as prior generations - whether changing the conditions of childhood in one generation might weaken social structures in the next and thereafter impact negatively on childhood generation after generation. ${ }^{84}$ Instead of planning for possible negative side-effects of "modern" parenting and schooling (having left its former beneficiaries in control of child-rearing discourse), the

82 I use the term "psychosociological system" to differentiate the model used by the mental hygienists to describe the process of personality formation from its mass application by the mental hygiene movement - to distinguish the seed from its fruit, to employ an orchard metaphor of which Frank was particularly fond. The psychobiological model advanced by Meyer was a psychiatric construct that explained the process of personality formation in an individual. The mental hygiene project was a systematic, mass application of that model, a practical intervention into the affective conditions of childhood. The difference between the terms is a difference between origins and outcome, model and application, a matter of scale, intent, design, process, and system. 83 Bruch, Don't Be Afraid of Your Child, 259.

84 The question arises, of course, whether parents did follow psychological advice in significant numbers. Canada's senior childhood historian, Neil Sutherland, contends that there is no direct evidence that they did. On the other hand, there is no evidence that they did not. Logic would seem to dictate that given the omnipresence of the advice, parents were not likely to reject it en bloc: thus the real question becomes "to what degree did they follow it?” Applying the Meyer model, altering social relations within a major social structure, such as the family or the school, should condition a mass change in personality. If families had changed their child-rearing practices in large numbers, then, one would expect some manifestation of a personality change in equally large numbers of children. I contend that the events of the "counter-culture" in the late-1960s and early 1970s (when the first wave of the baby boomers reached the age of majority) is one such manifestation of this mass personality change; another is the dramatic rise in divorce rates in the early 1980 s, a phenomenon led by the baby boom generation. 
RF switched its funding priorities in 1939 to a new project: mass communications research. ${ }^{85}$

\section{Mass Communications Research and Children}

As Timothy Glander notes in his Origins of Mass Communications Research During the American Cold War, "Even before the war broke out in 1939, there was a significant and growing body of researchers concerned with problems of social control through the use of the mass media." "World War II accelerated this trend, creating a demand for mass communications research that Rockefeller philanthropy was keen to foster. ${ }^{87}$ The Rockefeller Communications Seminars of 1939-1940 included communications notables such as Harold Lasswell and Paul Lazarsfeld and led to the institutionalization of mass communications research as an important field of study on post-World War II university campuses.

As Glander observes, "Memoranda that grew out of the Rockefeller Foundation discussion groups made it clear that several of the founding figures in the field [including Lazarsfeld and Lasswell] regarded the development of conformity of opinion as the main goal of their research." ${ }^{88}$ Funds for research into mass communications flowed steadily from the philanthropy from 1939 through the 1950s - often to the same institutions that earlier had received Foundation funding for child studies. Yale and Princeton Universities were major recipients of Rockefeller funding for communications research. From 1946 to 1961, Yale University established a program of research into communications and attitude change - largely supported by RF funding - in which more than fifty long-term experiments were

85 John Marshall, an officer of the Rockefeller Foundation, coined the term "mass communications" in his letters inviting scholars to participate in the 1939-1940 Rockefeller Communications Seminar. See Wilbur Schramm, The Beginnings of Communications Studies in America (Thousand Oaks, California: Sage Publications, 1977), 135.

86 Glander, Origins of Mass Communications Research During the American Cold War, 40.

87 Schramm, The Beginnings of Communication Study in America, 135.

88 Glander, Origins of Mass Communications Research During the American Cold War, 47. 
carried out on the effects of communications' messages. ${ }^{89} \mathrm{At}$ Princeton (and later at Columbia University), Lazarsfeld, one of the "founding fathers" of mass communications research, likewise received generous Rockefeller funding to study the effects of radio communications on listeners. ${ }^{90}$

In general, mass communications researchers such as Lasswell and Lazarsfeld worked within funding parameters that limited the scope of their research. The Rockefeller Charter for the Princeton Office of Radio Research (The Princeton Project), for example, stipulated that "[the commercial radio system's] cultural and sociological consequences and its social and economic presuppositions were not to be analyzed." 91 Moreover, researchers could work only on those problems defined as such by funding sources. ${ }^{92}$ Despite these somewhat restrictive research conditions, in contrast with its parent education project, the RF encouraged pluralistic research for mass communications studies - except in one key case: it declined to fund studies into resistance to mass communications and thereby marginalized such research. ${ }^{93}$ In one notable case, the "Institute for Propaganda Analysis," founded by Columbia University Teachers College professor, Clyde Miller, was refused RF financial support on the basis that the Institute's work was not "unassailably scientific." Miller had proposed to "formulate methods whereby citizens could make their own analysis of attempts to persuade them." 94

Children understandably became an important focus group for post-World War II mass communications researchers. As Gordon W.

89 Funding also flowed from the Central Intelligence Agency (CIA), especially after 1960. In 1977, it became known that the CIA had funnelled \$193,000 through a front organization to the Institute of Communications Research at the University of Illinois from 1960 to 1963, "to develop methods of mind control.” Ironically, even the Standard Oil Company occasionally co-funded RF Mass Communications Research. See ibid., 79, 92, 155.

90 Somewhat incongruously, in a 1948 article written in collaboration with Robert K. Merton of Columbia University, Lazarsfeld and Merton addressed the power of the media and the dangers of manipulation of the media by interest groups. The authors stated: "It is widely felt that the mass media comprise a powerful instrument that may be used for good or ill and that, in the absence of adequate controls, the latter possibility is on the whole more likely.” Paul F. Lazarsfeld and Robert K. Merton, "Mass Communication, Popular Taste, and Organized Social Action," in The Communication of Ideas: A Series of Addresses, ed. Lyman Bryson (New York: Cooper Square Publishers, [1948]), 95.

91 Glander, Origins of Mass Communications Research During the American Cold War, 128.

92 Ibid.

93 Ibid., 24.

94 In 1939, Miller's institute came under investigation by the House Committee on Un-American Activities "to ascertain whether its aims were dangerous to about 1,000,000 school pupils.” Ibid. 
Allport (co-author with the RF's John Marshall of The Psychology of Radio in 1935) declared in 1947, "To overlook children is to be stupidly inefficient from the standpoint of social engineering... Social scientists might reasonably advise that adults be largely disregarded in favor of children." 95 Indeed, communications researchers made several significant discoveries during the next two decades concerning the importance of children in the flow of information to adults, suggesting, as to Jules Henry in 1963, that "since in contemporary America children manage parents, the formers' brain box is the antechamber to the brain box of the latter." 96

In one important theoretical breakthrough, Lazarsfeld advanced a paradigm in the early era of television for changing social attitudes in a single generation through the media suppression of attitudes among the adult population and substitution of new attitudes in the rising generation. In theory - to apply Lazarsfeld's construct attitudes commonly held within the adult population could be suppressed through the humiliation of media characters that held such attitudes. Media shaming would suppress real adults who held the same attitudes, inhibiting their interference while new attitudes were substituted in the new generation - who in time would become an adult population with an approved attitude. Suppression and substitution in effect may be seen in television's influence over race and gender attitudes (recall All in the Family and Sesame Street in the mid-1970s) and may be more recently connected to the remarkable turnaround in attitudes toward gays and lesbians in North America. ${ }^{97}$

In the main, the findings of the early RF mass communications researchers were as applicable to children and youth as they were to adults. Indeed, the discovery of a "two-step flow of communication" as described in Lazarsfeld and Elihu Katz's book, Personal Influence: The Part Played by People in the Flow of Mass Communications (a work considered pivotal in the field's history) seems particularly pertinent to adolescents, whose social attitudes are to a great extent contained

95 Gordon W. Allport, "Guide Lines for Research in International Cooperation,” Journal of Social Issues III, 1 (Winter 1947): 29. Allport believed that radio would be a boon to the development of democracy, because it helped to create the "crowd mind" that he saw as a necessary characteristic of a democracy. See Glander, Origins of Mass Communications Research During the American Cold War, 87.

96 Jules Henry, quoted in Glander, Origins of Mass Communications Research During the American Cold War, 79. See in particular Glander's survey of the "Paul Revere Studies" in Alabama and Utah, ibid., 7-8.

97 Paul F. Lazarsfeld, "Some Remarks on the Role of the Mass Media in So-called Tolerance Propaganda,” Journal of Social Issues III, 3 (Summer 1947): 17-25. Wrote one observer of Sesame Street, "The show catches the pre-schooler almost before his society does." Thomas D. Cook et al., "Sesame Street" Revisited (New York: Russell Sage Foundation, 1975), 37. 
within their peer group. Briefly stated, the "two-step" or "personal influence" paradigm argued that mass communications messages do not influence the entire population directly, but rather are filtered through "opinion leaders" who diffuse the message to others within their social domain. ${ }^{98}$ Applying this finding to the prospect that postWorld War II parents and teachers followed the advice of mental hygiene psychologists and relaxed their authority over children, they would have inadvertently weakened their influence over the social attitudes of children and (applying the logic of the Meyer model) strengthened the hand of children's peer groups - whose social domain had not been penetrated by the mental hygiene movement and whose opinion leaders might well appear as youthful characters on television. ${ }^{99}$

As early as 1933, a series of studies concerning the emotional, physiological, and social effects of motion pictures upon youth, the Payne Fund Studies (PFS), had been released and were widely known. Among the credible findings of the educators, psychologists, and sociologists who published in the twelve-volume MacMillan series entitled Motion Pictures and Youth were these conclusions produced by two University of Chicago sociologists, Herbert Blumer and Philip Hauser: "The influence of motion pictures seems to be proportionate to the weakness of the family, school, church, and neighborhood. When the institutions which traditionally have transmitted social attitudes and forms of conduct have broken down... motion pictures assume a greater importance as a source of ideas and schemes of life."100 Motion pictures, the PFS established, had enormous potential as a medium for socializing children at a distance, but, as it stood, their influence over children was effectively counterbalanced by existing family, school, and community structures - the very structures that had become the focus for reform by Rockefeller philanthropy.

98 Elihu Katz and Paul F. Lazarsfeld, Personal Influence: The Part Played by People in the Flow of Mass Communications (Glencoe, Ill.: Free Press, 1955). See also Glander, Origins of Mass Communications Research During the American Cold War, 107.

99 Wilbur Schramm, a co-founder of mass communications research with Lasswell and Lazarsfeld, had observed as early as 1949 that "television has the power to produce social changes of great magnitude [since] television is proving more attractive to children than radio." Schramm, quoted in Glander, Origins of Mass Communications Research During the American Cold War, 137.

100 Herbert Blumer and Philip M. Hauser, Movies, Delinquency, and Crime (New York: MacMillan, 1933), 202. 
IN HER BRILLIANT 1995 study, The Romance of American Psychology: Political Culture in the Age of Experts, Ellen Herman notes that by the mid-1930s the concept of "national character" was in ascendance among influential progressive thinkers like Frank. Originating from the work of cultural anthropologists, such as Gregory Bateson, Ruth Benedict, Margaret Mead, and Edward Sapir, at the heart of the concept lay a compelling logic: if individuals embodied their society and societies embodied the collective personality of their people, then the institutional vehicles of socialization for a nation, from childrearing to teacher training, worked to produce a collective personality structure - that is, a national character.

In a pivotal 1936 article, Lawrence K. Frank, an advocate of clinical approaches whose influential foundation posts had included the Rockefeller Foundation and the Josiah Macy, Jr. Foundation, pointed out that if nations had characters, then it made sense to think of society as the patient. ${ }^{101}$

Society - the patient - could be remedied, or so it seemed, by reforming its character through its socializing structures. By 1936, the prescription had become a two-step treatment that shifted weight in the socializing matrix from parents and teachers via the mental hygiene movement to the peer group and the media. To remedy the national character, Rockefeller philanthropy had funded the implantation of mental hygiene principles into families and schools, the primary socializing structures for American and Canadian children, while leaving intact other important social environments a psychiatric treatment with the potential to condition a mass personality less resistant to peer group and media socialization. By transplanting its funding to mass communications research (and assured of a trend of diminished control of parents and teachers over the socialization of children), Rockefeller philanthropy had made it conceivable by the 1960 s to manage attitudes and predispositions within society on a massive scale through the national mass media. ${ }^{102}$

101 Ellen Herman, The Romance of American Psychology: Political Culture in the Age of Experts (Berkeley: University of California Press, 1995), 35.

102 As educator Philip H. Phenix observed a quarter century later in Phi Delta Kappan 43 (October 1961): 15: "We have entered an era in which the mass media may be the real public schools - the institutions in which the public is not only formed and instructed but also brought into being as a public with common standards and assumptions.” Ironically, the first national television network in the United States, the National Broadcasting Corporation opened its offices in Rockefeller Plaza in New York City in the 1930s. 
Rockefeller philanthropy, with its hegemony over the production and dissemination of child-rearing knowledge, was the hand that rocked the cradle in the post-World War II era. In so doing, it set the stage for the formation and perpetuation of what C. Wright Mills and others would come to describe as "mass society" - that is, "the transformation of a community of publics into an increasingly homogenized, standardized, and bureaucratized whole, which could be managed through the centralized power of an elite equipped with increasingly sophisticated means of social control." 103 For good or ill, intentionally or not, the hand that rocked the cradle was shaping the national character into a form and likeness conditioned to be ruled. ${ }^{104}$

103 C. Wright Mills, in Glander, Origins of Mass Communications Research During the American Cold War, 183. Glander observes that "it is a fundamental curiosity that since World War II, as mass media in the US have become more concentrated in ownership, more centralized in operations, more national in reach, more pervasive in presence, sociological study of the media has been dominated by the theme of the relative powerlessness of the broadcasters.” Glander, ibid., 241.

104 For Erich Fromm, in his The Sane Society (New York: Holt, Rinehart \& Winston, 1955), 296-98, the remedy to mass society was to be found in returning to small-group discussion and genuine community life. This could be set in motion, I suggest in NFB Kids, with a two-step process returning social power to families and the schools of their communities. 